\title{
UM CASO DE ENSINO SOBRE O SISTEMA DE NUMERAÇÃO DECIMAL COMO MEIO DE IDENTIFICAÇÃO E FORMAÇÃO DE SABERES DE FUTUROS PROFESSORES DE MATEMÁTICA
}

\author{
Raquel Gomes de Oliveira ${ }^{20}$
}

\section{RESUMO}

Este artigo é sobre uma pesquisa qualitativa interpretativa que analisou a utilização de um caso de ensino como meio de identificação e de elaboração de saberes docentes de licenciandos de Licenciatura em Matemática de uma universidade pública do interior de São Paulo. O caso de ensino versava sobre o Sistema de Numeração Decimal (SND) e oportunizou aos licenciandos a vivência do processo de diagnóstico, de compreensão de dificuldades e de avaliação em situações didático-pedagógicas. A análise dos resultados evidenciou que a clareza dos licenciandos quanto às características do SND, em termos de agrupamento e posicionalidade, mostra-se pertinente para a elaboração de saberes docentes referentes à compreensão da natureza e da origem dos erros cometidos pelos alunos do caso de ensino. Igualmente essa clareza permitiu realizar questões e ações relacionadas à prática pedagógica. Os resultados indicam que saberes docentes podem ser desenvolvidos a partir da qualidade da relação entre o saber do licenciando e o saber apresentado pelos alunos no processo de ensino e aprendizagem. Concluiu-se que as simulações didático-pedagógicas vivenciadas em um caso de ensino podem ser entendidas como meio de desenvolvimento de saberes docentes na formação inicial de professores.

Palavras-chave: Caso de Ensino. Sistema de Numeração Decimal. Saberes e Formação de Professores.

\section{A TEACHING CASE ABOUT THE DECIMAL NUMBERING SYSTEM AS A MEANS OF IDENTIFICATION AND KNOWLEDGE ELABORATION OF MATHEMATICS FUTURE}

\section{TEACHERS}

\section{ABSTRACT}

This article is about a qualitative interpretive research that analyzed the use of a teaching case as a means of identification and elaboration of teaching knowledge of undergraduated students of Mathematics from a public university in the interior of São Paulo. The teaching case was about the Decimal Numbering System (SND) and

20 Doutorado em Educação pela Universidade de São Paulo. Docente do Programa de PósGraduação em Educação da Faculdade de Ciências e Tecnologia-FCT-UNESP. E-mail: raqueloliveira@fct.unesp.br. 
gave the licenciandos the experience of the process of diagnosis, understanding of difficulties and evaluation in didactic-pedagogical situations. The analysis of the results showed that the clarity of the Mathematics undergraduate students regarding the characteristics of the SND, in terms of grouping and positionality, is relevant for the elaboration of teacher knowledge regarding the understanding of the nature and origin of the mistakes made by students in the teaching case. This clarity also allowed the elaboration of questions and actions related to pedagogical practice. The results indicate that teacher knowledge can be developed based on the quality of the relation between the knowledge of the Mathematics future teacher and the knowledge presented by the students in the process of teaching and learning. It was concluded that the didactic-pedagogical simulations experienced in a teaching case can be understood as a means of developing teacher knowledge in the initial teacher training.

Keywords: Teaching Case. Decimal Numbering System. Knowledge and Teacher Training.

\section{UN CASO DE UN MEDIO DE IDENTIFICACIÓN Y CONOCIMIENTO DE LA FORMACIÓN DE FUTUROS PROFESORES DE MATEMÁTICAS DE ENSEÑANZA ACERCA DE EL COMO DE SISTEMA DE NUMERACIÓN DECIMAL}

\section{RESUMEN}

Este artículo es acerca de una investigación cualitativa interpretativa que examinó el uso de un caso de la enseñanza como un medio de identificación y elaboración de maestros conocimiento de licenciandos de grado en matemáticas por la Universidad de estado de São Paulo. El caso de la enseñanza era sobre el sistema de numeración Decimal (SND) y permitió a licenciandos la experiencia del proceso de diagnóstico y las dificultades de la evaluación de la comprensión en situaciones didácticas pedagógicas. El análisis de los resultados mostró que la claridad de las características de licenciandos de la SND, en términos de agrupación y posicionalidade, es relevante para el desarrollo de los docentes de conocimientos referente a la comprensión de la naturaleza y origen de los errores cometidos por los estudiantes del caso. Esto claramente permitió realizar cuestiones y acciones relacionadas con la práctica pedagógica. Los resultados indican que se puede desarrollar conocimiento de maestros de la calidad de la relación entre el conocimiento de las licencias y conocimiento presentado por los alumnos en la enseñanza y aprendizaje. Se concluyó que las simulaciones didácticas pedagógicas experimentaron un caso de la enseñanza puede entenderse como un medio de desarrollo de los conocimientos docentes en formación inicial del profesorado.

Palabras clave: Educación. Sistema de Numeración Decimal. Conocimiento y Formación de Professores. 


\section{INTRODUÇÃO}

Pesquisar sobre saberes docentes, pode-se hoje afirmar, tem origem com o questionamento e críticas a vários enfoques que buscavam explicar, entender, e até mesmo direcionar processos de ensino e aprendizagem. Necessariamente a mudança do foco de "o que fazem os professores" para "o que sabem os professores" levou às investigações de um corpo de conhecimento para o ensino ou uma base de conhecimento).

Assim, antes de se constituir propriamente num problema teórico, o knowledge base assumiu a forma de uma solicitação social: era preciso melhorar a formação docente e favorecer sua profissionalização para melhorar a educação (MONTEIRO, 2003, p.3).

Diante do enfoque sobre o que sabem os professores, é possível ter a pertinência da questão da pesquisa: como o conhecimento de futuros professores de Matemática sobre Números e Operações pode ser identificado e transformado em saberes docentes, especificamente quanto ao conhecimento matemático e sua representação, diante das dificuldades dos alunos ingressantes nas séries finais da Educação Fundamental?

A resposta a esta questão pode variar conforme o ponto de vista de quem a responde. Se buscarmos respondê-la tendo em vista que um curso de Licenciatura em Matemática, através de disciplinas científico-culturais e pedagógicas, prepara o professor para dar aulas de Matemática nas séries finais do Ensino Fundamental e no Ensino Médio, fundamentados pelas Diretrizes Curriculares Nacionais para a Formação de Professores da Educação Básica (RESOLUÇÃO CNE/CP 01/2002), pelos Parâmetros Curriculares Nacionais (BRASIL, 1998) e particularmente pelo Projeto Político Pedagógico de curso de Licenciatura, responderemos que, de modo geral, a formação inicial do professor de Matemática deve oportunizar ao futuro professor o desenvolvimento de diversos saberes, entre eles saberes específicos e saberes gerais, a fim de prepará-lo para ensinar efetivamente, isto é, objetivando que o aluno aprenda. Assim, através de um Curso de Licenciatura ou com a formação inicial, o professor já teria condições de 
alcançar o objetivo de ensinar conceitos matemáticos para seus alunos na Educação Básica.

Igualmente essa resposta já poderia ter sido apresentada caso não se atentasse para a condição de se referir a saberes docentes contextualizados, ou seja, ao fato de que devem existir diante de dificuldades dos alunos ingressantes nas séries finais da Educação Fundamental, requisitando, portanto de competências profissionais específicas para este contexto de prática docente.

É nesse sentido que a ideia de coerência entre a formação inicial de professores de Matemática e as realidades escolares leva a entender que os saberes docentes necessários para enfrentar dificuldades dos alunos ingressantes nas séries finais da Educação Fundamental necessitam ser investigados à luz dessas dificuldades apontadas, sobretudo por sistemas de avaliação de rendimento como, por exemplo, o Sistema de Avaliação de Rendimento Escolar do Estado de São Paulo (SARESP). Ou seja, parte da resposta à pergunta, colocada no início deste texto, depende de outra questão: quais são as dificuldades em Matemática dos alunos ingressantes nas séries finais do ensino fundamental?

A partir da problemática apresentada, a pesquisa objetivou analisar a utilização de um caso de ensino, como meio de identificação, elaboração e representação de saberes docentes, junto a futuros professores de Matemática. Os resultados mostraram que existem níveis (excelente e satisfatório) nos quais os licenciandos procuram intencionalmente transformar conteúdo matemático em conteúdo de ensino, o mesmo não ocorrendo no nível insatisfatório. Os resultados evidenciaram também que o conhecimento necessário para se ensinar pode ser desenvolvido e ampliado na relação docente com competências e habilidades apresentadas pelos alunos do caso de ensino. Concluiu-se que um caso de ensino sobre conceitos matemáticos pode ter reconhecido lugar como meio de identificação e desenvolvimento de saberes docentes na formação inicial de professores. 


\section{DOS SABERES DOCENTES OU DO QUE DEVE SABER UM PROFESSOR PARA ENSINAR: a questão do retorno ao conteúdo de ensino}

A ação de ensinar ou a atividade docente a partir do reconhecimento do fazer docente enquanto profissão, que possui saberes próprios e que acontece sob a intersecção de contextos (sociedade, comunidade, escola, sala de aula, relação professor-aluno-conteúdo...) implicou revisão e ampliação dos conhecimentos que a compõem ou que a deveriam compor.

Para García (1999) a formação inicial de professores é um campo de problematizações que justificam pesquisas, porque se constitui tanto como uma fonte de preocupação com um elemento de estudo e, a partir dele, de toda uma discussão sobre o porquê e o para que formar um professor. Apesar de se referir ao que chamou de componentes gerais da formação de professores, García (1999) opta por focar no que denominou de áreas específicas de formação: conhecimentos (que devem abranger o saber pedagógico, o saber-fazer e o saber o porquê de fazer), competências e atitudes.

O conhecimento pedagógico geral é o que permite, de acordo com García (1999), ao professor obter o título de "qualificação pedagógica".21 Esse conhecimento diz respeito a questões mais amplas da Educação, tais como: seus princípios gerais, a relação escola-comunidade, conhecimentos gerais e crenças sobre teorias da Educação e práticas de ensino.

O conhecimento da matéria a ser ensinada se justifica há tempos por pesquisas e crenças, entre as quais, saber bem um conteúdo é condição imprescindível para ensiná-lo. Uma das explicações para esta relação entre saber e saber-fazer pode ser justificada assim: "Conhecer algo, permite-nos ensiná-lo; e conhecer um conteúdo em profundidade significa estar

${ }^{21}$ García (1999) faz uma referência à necessidade de formação pedagógica estabelecida pela LOGSE (Lei Orgânica de Ordenamento Geral do Sistema Educativo: Lei maior da Educação espanhola) quando da passagem de professores de um nível a outro. 
mentalmente organizado e bem preparado para $\mathrm{O}$ ensinar de um modo geral". (BUCHMANN, 1984 apud GARCÍA, 1999, p. 87).

De acordo com Oliveira (2006) especificamente nos trabalhos de Shulman (1986, 1987 e 1989) existe a defesa sobre as diferenças entre o que o professor conhece, e como ele organiza, justifica e valida o quê conhece. Nesses trabalhos encontra-se a crítica sobre pesquisas que somente mostram e pontuam o que o professor conhece e falham no sentido de mostrar como ou de que modo esse conhecimento que o professor tem é desenvolvido, enriquecido e usado em sala de aula.

Para Shulman (1986) o conteúdo do ensino foi ignorado dada a simplificação, por parte de alguns pesquisadores, das complexidades próprias do ensino, existentes em sala de aula.

Essa predisposição dos pesquisadores educacionais para favorecem, em situações de ensino, as questões educacionais mais gerais em detrimento do próprio conteúdo de ensino é denominada por Shulman (1986) de "Paradigma Perdido". Nesse sentido, o conteúdo do ensino é mais uma variável entre todas aquelas consideradas na pesquisa. Portanto, para Shulman $(1986,1987)$ as pesquisas falham por não investigarem como o conhecimento do professor é transformado em conhecimento para o ensino.

Uma das referências de competência docente é a capacidade do professor para variar seus esquemas ou modos de representações sobre o conteúdo que domina. Essa capacidade de variação de representações do professor faz com que o mesmo mova-se de sua própria compreensão do assunto para o encontro de representações mais úteis aos alunos, estimulando-os a representarem de diversas maneiras, proporcionando, em sala de aula, uma variedade de representações (WILSON, SHULMAN, RICHERT, 1987).

Parte do trabalho de Shulman é baseada em suas pesquisas que traçam a biografia intelectual de professores iniciantes, desde seus Estágios Supervisionados até aproximadamente o segundo ano como professores nas escolas. As biografias intelectuais desses professores permitiram que Shulman 
(1986) levantasse duas categorias para uma análise conceitual do conhecimento do professor: o conhecimento do professor sobre um conteúdo e as formas de representar esse conhecimento. Para o conhecimento do conteúdo, Shulman (1986) aponta categorias de conhecimento, tais como: conhecimento do próprio conteúdo; conhecimento pedagógico do conteúdo e conhecimento curricular do conteúdo.

Já para representar as categorias do conhecimento são propostas três maneiras: conhecimento proposicional (princípios, máximas e normas); conhecimento de caso ou de eventos específicos e muito bem documentados, que permite reflexões, reelaborações e possibilita aplicações em outras situações e conhecimento estratégico que implica rastrear o que se aprendeu e fazer escolhas de ação diante da situação que se apresenta.

Ao considerar outras formas de conhecimento para o professor, do mesmo modo que outras maneiras para representá-lo, depreende-se de Shulman que os professores necessitam bem mais do que um entendimento pessoal do assunto a ser ensinado. Citando Dewey (1859-1952), Shulman (1987) defende que o conteúdo a ser ensinado pelo professor deve ser psicologizado, reelaborado em vista do ato de ensinar, sendo assim transformado em conteúdo de ensino. Essa transformação envolve as capacidades do professor de representar por várias maneiras (metáforas, associações, exemplos, parábolas, desenhos, recursos mnemônicos, gráficos...) este conteúdo de modo a contribuir tanto para as representações iniciais que os alunos possam ter do conteúdo, e ainda para a possibilidade de que os mesmos façam reelaborações em sentidos cada vez mais avançados e próximos do conhecimento escolar.

Tendo como referência os resultados de um estudo longitudinal sobre o desenvolvimento do conhecimento para ensinar, precisamente a tentativa de mapear a passagem do "aprendiz experiente" ao "professor novato", Wilson, Shulman e Richert (1987) sugerem que os professores iniciantes, 
quando se preparam para ensinar e quando estão ensinando, desenvolvem outro tipo de conhecimento que se articula com o conhecimento do aluno, do currículo, do contexto, da pedagogia. Esta nova forma de conhecimento foi denominada como conhecimento pedagógico do conteúdo porque

[...] encarna os aspectos do conteúdo mais genuínos para sua ensinabilidade. Dentro da categoria do conhecimento pedagógico do conteúdo inclui os tópicos mais regularmente ensinados em qualquer área, as mais úteis formas de representação das idéias relacionadas a esses tópicos, as mais poderosas analogias, ilustrações, exemplos, explicações e demonstrações - em uma palavra, os modos de representar e reformular o conteúdo de maneira a torná-lo compreensível aos outros [...] (SHULMAN, 1986, p.9).

$\mathrm{Na}$ perspectiva desse autor, o conhecimento pedagógico do conteúdo requer tanto o entendimento por parte do professor de que este vai ensinar um tópico particular e, portanto necessita saber princípios e técnicas para isso quanto a estruturação do tópico a ser ensinado em termos de como fazê-lo, de como os estudantes aprendem, das dificuldades que os mesmos encontram, bem como das habilidades desses estudantes para aprender e de suas concepções errôneas, além da organização do tópico em uma área do conhecimento e o porquê e como este tópico deve estar incluso no currículo.

Ao criticar pesquisas do passado, que buscaram relacionar estatisticamente o conhecimento do professor com o desempenho do aluno, Grossman, Wilson e Shulman (1989) denominaram essas pesquisas de "presságio-produto" (porque supunham que o conhecimento de um professor sobre um assunto poderia ser medido em termos da quantidade de aulas tomadas ou de cursos que o mesmo realizara sobre este assunto) e defendem que o conhecimento tanto do professor como do aluno vai muito além do que é medido em testes padronizados. "Por exemplo, o conhecimento de matemática de um professor pode incluir entendimento conceitual de equações quadráticas e diversos modos de representar esse 
conhecimento quando da habilidade para resolver um conjunto de problemas de fatoração" (GROSSMAN, WILSON, SHULMAN, 1989, p.25).

Contudo, outras pesquisas diferentemente de buscarem relacionar $\mathrm{O}$ conhecimento do professor com o desempenho do aluno buscaram e estão buscando explorar a natureza, a forma, a organização e o conteúdo do conhecimento do professor. Como exemplo, citada por Grossman, Wilson e Shulman (1989), a pesquisa de Calderhead e Miller (1985) sugere que o professor "entrelaça" seus conhecimentos anteriores com os conhecimentos imediatos oriundos do contexto de sala de aula, dos conhecimentos prévios e dos interesses dos seus alunos, de acordo com suas comunidades para obter um conhecimento-ação significativo ao que se apresenta para ambos.

Contribuindo para outros tipos de resultados de pesquisas, três categorias do conhecimento do professor são indicadas por Grossman, Wilson e Shulman (1989) como facilitadoras para aquilo que caracteriza o professor competente: o conhecimento substantivo do conteúdo, o conhecimento sintático do conteúdo e as crenças sobre o conteúdo que os professores possuem.

Nesse sentido, conhecer algo substantivamente é conhecê-lo em termos de conceitos e de estruturas organizadoras de uma disciplina sem espaços para discussões sobre as maneiras pelas quais este conhecimento passou a fazer parte do campo disciplinar. Na sala de aula, por exemplo, não há momentos para discussões, fóruns, seminários que levem à interpretação do conhecimento fundamentada em bases históricas, filosóficas e contextuais. Já o conhecimento sintático é relacionado com os modos, os métodos que fazem com que um novo conhecimento seja incorporado no campo de uma disciplina. É a alusão ao conhecimento em bases históricas, filosóficas e contextuais juntamente com a consciência do que é possível ou não, do que é suficiente ou não, através da investigação ou da pesquisa. 
Para Grossman, Wilson e Shulman (1989) a relevância do conhecimento sintático está na consequência pedagógica no ato de ensinar: "Para professores com conhecimento sintático, uma aula de biologia não é apenas a memorização do filo, esta inclui discussões e atividades que ajudam no desenvolvimento da consciência nos estudantes do papel central do método científico" (GROSSMAN, WILSON E SHULMAN, 1989, p. 30).

Outra categoria de conhecimento que afeta o modo como um tópico será ensinado são as crenças que os professores têm sobre um assunto. As crenças são, neste caso, entendidas bem mais como conhecimentos referendados por avaliações pessoais e afetivas, portanto subjetivas do que objetivas. Diferentemente do conteúdo sintático, as crenças são libertas de critérios de evidência.

O primeiro tipo de crença, proposto por Grossman, Wilson e Shulman (1989), refere-se à natureza do conteúdo a ser ensinado. Assim, se este conteúdo é interpretado pelo professor como de pouco ou de nenhum interesse para seus alunos, possivelmente este professor reorganizará este conteúdo em termos do currículo e do modo como trabalhará com o mesmo em sala de aula. O segundo tipo de crenças é chamado de "orientação" quanto ao assunto. Deste modo, as diferentes orientações dos professores quanto a um assunto leva-os a terem diferentes concepções do que é necessário conhecer e sobre como alguém consegue conhecer, o que resulta em diferentes maneiras de agir em sala de aula, de escolher as atividades, de avaliar.

A defesa de Shulman (1986, 1987) sobre a necessidade de transformação do conteúdo do professor, no sentido de que se torne conteúdo de ensino, não torna menos complexo o processo de ensino e aprendizagem. Contrariamente, as categorias do conhecimento, que devem fazer parte da profissão professor, nos termos em que são discutidas por Grossman, Wilson e Shulman (1989), contribuem para o entendimento dessa complexidade, buscando desde a formação inicial, situações de 
ensino e de iniciação à vida profissional, a conscientização e a reelaboração dessas categorias, por parte dos futuros professores.

\title{
CASOS DE ENSINO E SUAS POTENCIALIDADES PEDAGÓGICAS
}

Como visto, Shulman (1986) propõe a existência de uma base de conhecimento para o ensino, considerada essencial e única, denominada conhecimento pedagógico do conteúdo, que deve ser originada em uma estrutura que classifique tanto as categorias de conhecimento docente (conhecimento do próprio conteúdo, conhecimento pedagógico do conteúdo; conhecimento curricular do conteúdo), quanto as formas de representá-lo (conhecimento proposicional, conhecimento de caso e conhecimento estratégico), sendo este marcadamente presente nos cursos de formação inicial de professores.

Mesmo reconhecendo a utilidade dos princípios, máximas e normas que compõem o conhecimento proposicional e que acabam simplificando algo considerado complexo, Shulman (1986) critica o excesso deste conhecimento na constituição do saber docente argumentando que

\begin{abstract}
A fraqueza das proposições é dupla. Em primeiro lugar, tornar-se muito difícil de lembrar, especialmente quando elas se agregam em longas listas. Este é o lugar onde estruturas teóricas como andaimes intelectuais tornam-se indispensáveis. Em segundo lugar, elas ganham a sua economia precisamente porque são descontextualizadas, sem seus fundamentos, desprovidas de detalhes, emoção, ou ambiência. No entanto, para ser lembrada e sabiamente usadas é precisamente o detalhe e o contexto que podem ser necessários. Embora os princípios sejam poderosos, eles não são particularmente memoráveis, tornando-se um problema para aplicar em circunstâncias particulares. Como fazer um professor aplicar, por exemplo, o princípio de "verificar a compreensão", certamente entre os mais importantes na instrução direta e as bases de pesquisa ativas de ensino? Por estas razões, estou propondo olhar seriamente para a utilidade de um segundo tipo de conhecimento, um complemento necessário ao conhecimento de proposições, o conhecimento de caso (SHULMAN, 1986, p.11).
\end{abstract}

A fraqueza sugerida por Shulman (1986) para o conhecimento que se pode originar através de proposições o fez propor um segundo tipo de conhecimento, considerado um complemento necessário para o 
conhecimento proposicional: o conhecimento de caso (case knowledge), que não deve ser entendido como apenas uma descrição de fatos.

A potencialidade pedagógica argumentada por Shulman (1986), para que o conhecimento de caso contribua para a formação de uma base de conhecimento para o ensino, reside na sua própria definição para um caso de ensino na qual conhecimento de caso é conhecimento sobre eventos específicos, bem documentados e ricamente descritos. [...] eles podem ser exemplos de princípios, exemplificando através de seus detalhes tanto uma proposição abstrata quanto uma alegação teórica (SHULMAN, 1986, p. 11). Ou seja, a alegação teórica antecede a denominação de um caso ao se buscar sempre responder: caso de quê?

A potencialidade pedagógica, que se pode ter ao utilizar um caso de ensino, pode ser oriunda de afirmações de Shulman (1996), tais como:

[...] um caso educacional é mais que uma boa narrativa, mais do que uma justaposição sábia de intenções e vicissitudes. [...] é uma forma de comunicação que coloca intenção e acaso no contexto de uma experiência vivida e refletida. [...] não apenas acontece; ele cria condições que exigem de seu narrador (ou protagonista) que considere tanto julgamentos entre rotas alternativas como aja em relação a tais julgamentos. Um caso tem conseqüências. Aprende-se a partir do deliberar reflexivamente sobre as relações entre os elementos de um caso. [...] um caso educacional combina, pelo menos, quatro atributos ou funções: intenção, possibilidade, julgamento e reflexão. Estas são funções que explicam ou delineiam o poder educativo dos casos para aprendizagem [...] (SHULMAN, 1996, p. 207).

Nesse sentido, na utilização de casos como estratégia de ensino destacam-se operações de pensamento como: análise, interpretação, crítica, reflexão, deliberação, levantamento de hipóteses, julgamento, decisão (SHULMAN, 1996; ANASTASIOU E ALVES, 2006).

No ensino ainda não se tem [...] um conjunto de casos de ensino construídos por professores que possam ser analisados entre si (HIEBERT, GALLIMORE, STIGLER, 2002 apud NONO, MIZUKAMI, 2002, p.74). Apesar disto pesquisas apontam a eficácia da utilização de casos de ensino enquanto instrumentos que possibilitam processos formativos e investigativos (MERSETH, 
1996; NONO, 2001; NONO E MIZUKAMI, 2002; NONO E MIZUKAMI, 2005) para a base o conhecimento do professor, tanto na formação inicial quanto na formação contínua deste.

Especificamente quanto à formação do conhecimento pedagógico do professor, Nono e Mizukami (2002) afirmam a possibilidade de se obter vantagens com a utilização de casos de ensino nesta formação, dado que

Entre tais vantagens, podemos destacar: auxílio no desenvolvimento, pelo professor, de destrezas de análise crítica e de resolução de problemas; provocação de uma prática reflexiva; [...]; implicação do professor em sua própria aprendizagem profissional; [...] desenvolvimento do processo de raciocínio pedagógico, entendido como a forma de pensamento que permite ao professor a transformação de conteúdos em ensino. Ao analisar uma situação de ensino, o professor recorre a seus conhecimentos acadêmicos, suas experiências prévias, seus sentimentos, podendo examinar sua validade diante da complexidade das situações de sala de aula (NONO e MIZUKAMI, 2002, p. 74).

Já para a compreensão da utilização de casos de ensino, em termos de suas potencialidades formativas e investigativas, no que se refere à formação do conhecimento pedagógico do professor, Merseth (1996) sugere a investigação de casos de ensino na forma de, por exemplo, vídeos, textos escritos, entre outros e em conteúdo, tais como: Matemática, Educação Especial... Sugere ainda variações nos métodos de casos: como, onde, quando e por quem os casos poderiam ser usados.

De acordo com Merseth (1996), importantes contribuições sobre a pesquisa na área a qual se refere os casos de ensino dependerão da existência do desenvolvimento inicial de estudos que complementem o entendimento sobre os elementos envolvidos no ensino baseado em casos (materiais e métodos) como também de estudos que explorem a interação de materiais e casos com os que aprendem através do uso de casos de ensino. 


\section{PROCEDIMENTOS METODOLÓGICOS}

Para seu desenvolvimento, o projeto da pesquisa foi aprovado um Comitê de Ética em Pesquisa sob número 32347014.3.0000.5402. Os procedimentos para sua realização levaram a classificá-la como uma pesquisa qualitativa, de ações descritivo-interpretativas. Houve a utilização de um caso de ensino (Quadro 1) que foi elaborado pela pesquisadora, sendo composto por atividades relativas ao Sistema de Numeração Decimal (SND). As atividades do caso de ensino foram desenvolvidas com 15 licenciandos regularmente matriculados na disciplina Estágio Curricular Supervisionado II oferecida no $4^{\circ}$ ano do curso de Licenciatura em Matemática de uma universidade paulista pública. O SND foi escolhido como meio para verificar a existência e o desenvolvimento de saberes docentes, em conformidade com o trabalho pedagógico dos licenciandos, no que se refere a habilidades cognitivas que estruturam no aluno de $4^{a}$ série ou $5^{\circ}$ ano do ensino fundamental competências para observar, realizar e compreender.

Quadro 1: Caso de ensino analisado pelos licenciandos de Matemática

Jonas, Maria e André são alunos do $5^{\circ}$ ano de uma escola pública. Ao retornar do recesso do mês de julho, a professora Inês passou para a classe atividades sobre conteúdos trabalhados com os alunos desde o início do ano letivo até o recesso. A escola, onde Jonas, Maria e André estudam e a professora Inês leciona, possui biblioteca, sala de informática, quadra de esportes, pátio e todos os anos essa escola participa do Programa Nacional do Livro Didático (PNDL).

$\mathrm{Na} 1^{a}$ atividade proposta pela professora. Inês, os alunos deveriam representar no ábaco e depois desenhar no caderno a representação, separadamente, das quantidades: a) 426, b) 302 e c) 150. Ao acompanhar os alunos realizando a atividade, a professora observou as seguintes representações: 


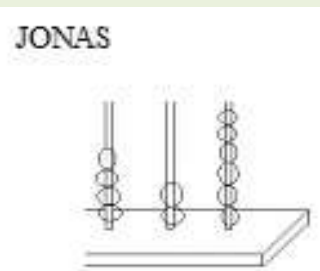

$1^{\circ}$ ábaco (426)

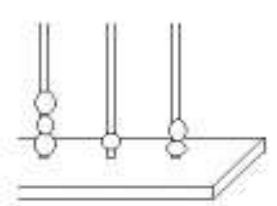

$2^{\circ}$ ábaco (302)

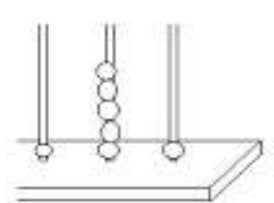

$3^{\circ}$ ábaco (150)

MARIA
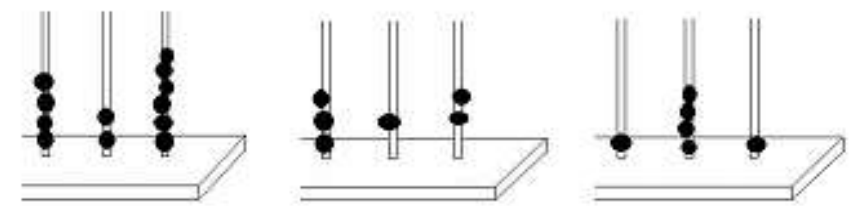

$1^{\circ}$ ábaco (426)

$2^{\circ}$ ábaco (302)

$3^{\circ}$ ábaco (150)

ANDRÉ

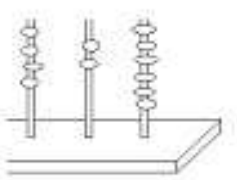

$1^{\circ}$ ábaco (426)

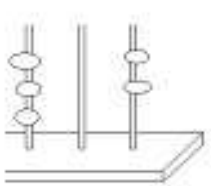

$2^{\circ}$ ábaco (302)

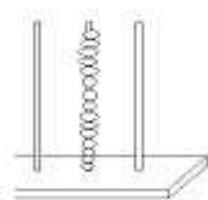

$3^{\circ}$ ábaco (150)

1) De acordo com as representações de Jonas, Maria e André, o que você acredita que esteja acontecendo em relação à decomposição de números naturais em diversas ordens? Elabore sua resposta para cada aluno.

2) Quais questões você faria para cada aluno para entender o que está acontecendo?

3) O que você faria diante das dificuldades apresentadas pelos alunos Jonas, Maria e André.

\section{Fonte: elaboração própria}

A elaboração do caso de ensino partiu de duas perspectivas: 1) a dos alunos, ao considerar suas dificuldades sobre o SND apresentadas em questões de provas do Sistema de Avaliação de Rendimento Escolar do Estado de São Paulo (SARESP) dos anos 2011, 2012 e 2013 e 2) a dos licenciandos ao considerar forma e conteúdo que permitiram identificar categorias de conhecimento que compõem o conhecimento pedagógico dos mesmos referente ao conteúdo em questão, além de categorias que indicam o desenvolvimento deste conhecimento. 
O caso de ensino que aborda conceitos sobre o Sistema de Numeração Decimal foi elaborado pela pesquisadora tendo como referência os dados de desempenho em provas sistematizadas, sobre o conteúdo Números e Operações, precisamente aqueles relacionados ao conceito de Sistema de Numeração Decimal, de alunos que ingressarão nos anos finais do ensino fundamental, ou seja, alunos do $5^{\circ}$ ano ou $4^{a}$ série. Os dados de desempenho no que tange às dificuldades dos alunos tiveram origem nas questões de provas do Sistema de Avaliação de Rendimento Escolar do Estado de São Paulo (SARESP) dos anos 201 1, 2012 e 2013.

A elaboração do caso de ensino considerou forma e conteúdo que permitiram identificar categorias de conhecimento que compõem 0 conhecimento pedagógico do conteúdo em questão, além de categorias que indicam o desenvolvimento deste conhecimento. As categorias foram descritas primeiramente em função de frequências de respostas dos licenciandos, o que levou à classificação dos mesmos nos níveis excelente, satisfatório e insatisfatório, conforme o Quadro 2. Quinze licenciandos participaram da primeira atividade com o caso de ensino na qual constavam questões de modo que com suas respostas foi possível identificar se estes: 1) percebem a compreensão errônea do aluno; 2) compreendem a razão ou o porquê do aluno demonstrar essa concepção errônea; 3) realizam questões apropriadas para revelar a compreensão errônea do aluno; e 4) avaliam com critérios apropriados as repostas dos alunos.

Os licenciandos receberam orientação para entregar suas respostas, que puderam ser dadas na própria folha de atividades. Igualmente esclareceu-se que não era necessária a identificação dos mesmos. Para a descrição dos resultados, a devolutiva dos licenciandos foi numerada de 1 a 15. Quanto às respostas das questões, verificou-se a existência dos itens de (1) a (4), sendo atribuído um ponto a cada item encontrado e zero para sua ausência. O somatório dos pontos permitiu classificar os licenciandos nos níveis excelente (4 pontos), satisfatório (3 e 2 pontos) e insatisfatório (1 e 0 
ponto). Essa classificação se identifica com os níveis propostos por Turnuklu e Yelsidere (2007) e dispostos no quadro 2.

Quadro 2: Níveis de desempenho para a análise de casos de ensino

\begin{tabular}{|l|}
\hline Nível 3: excelente (4 pontos) \\
\hline Percebem o erro cometido pelo aluno; \\
$\begin{array}{l}\text { - Compreendem a razão ou o porquê da concepção conceitual } \\
\text { do aluno expressa em seu erro; }\end{array}$ \\
\hline - Consegue realizar questões apropriadas para revelar a \\
concepção conceitual do aluno; \\
- Consegue avaliar a resposta do aluno com critérios apropriados. \\
- $\begin{array}{l}\text { Propõe atividades pedagógicas condizentes com as dificuldades } \\
\text { apresentadas pelos alunos. }\end{array}$
\end{tabular}

Nível 2: satisfatório (3 e 2 pontos)

- Compreende dificuldades dos alunos e compreende as razões dessas dificuldades;

- Consegue fazer questões apropriadas com o objetivo de entender o pensamento do aluno;

- Apresenta situações pedagógicas, somente através de questões, para superar a dificuldade apresentada pelo aluno;

\section{Nível 1: insatisfatório ( 1 e 0 ponto)}

- Percebe o erro dos alunos, mas não o associa às propriedades do Sistema de Numeração Decimal (SND);

- Apresenta dificuldade para entender tanto as dificuldades dos alunos bem como as razões dessas dificuldades;

- Não consegue fazer questões apropriadas com o objetivo de entender 0 pensamento do aluno nem consegue elaborar soluções para superar a dificuldade apresentada pelo aluno;

- Não propõe atividades pedagógicas condizentes com as dificuldades apresentadas pelos alunos.

Fonte: elaboração baseada em Turnuklu e Yelsidere, 2007 
Os dados foram analisados de modo quantitativo e qualitativo, não havendo associação, nem correlação entre variáveis ou categorias de análise e esta análise possui como objetivo responder a questões específicas com vistas a atingir o objetivo da pesquisa, além de propor questões que possibilitem justificar pesquisas posteriores. O quadro 2 sintetiza objetivos e procedimentos para a realização da pesquisa.

\section{RESULTADOS E DISCUSSÕES}

Nas respostas apresentadas pelos licenciandos foram identificados os dados que compõem a tabela 1.

Tabela 1: itens identificados nas respostas dadas pelos licenciandos

\begin{tabular}{|c|c|c|c|c|c|}
\hline Licenciando & Item (1) & Item (2) & Item (3) & Item (4) & $\begin{array}{c}\text { pontos } \\
\mathbf{e} \\
\text { classificação }\end{array}$ \\
\hline 1 & $\operatorname{sim}$ & não & não & não & 1: insatisfatório \\
\hline 2 & não & não & não & não & 0: insatisfatório \\
\hline 3 & $\operatorname{sim}$ & $\operatorname{sim}$ & não & $\operatorname{sim}$ & 3: satisfatório \\
\hline 4 & $\operatorname{sim}$ & $\operatorname{sim}$ & $\operatorname{sim}$ & $\operatorname{sim}$ & 4: excelente \\
\hline 5 & $\operatorname{sim}$ & $\operatorname{sim}$ & $\operatorname{sim}$ & não & 3: satisfatório \\
\hline 6 & $\operatorname{sim}$ & $\operatorname{sim}$ & $\operatorname{sim}$ & não & 3: satisfatório \\
\hline 7 & $\operatorname{sim}$ & $\operatorname{sim}$ & não & $\operatorname{sim}$ & 3: satisfatório \\
\hline 8 & $\operatorname{sim}$ & $\operatorname{sim}$ & $\operatorname{sim}$ & $\operatorname{sim}$ & 4: excelente \\
\hline 9 & $\operatorname{sim}$ & não & não & $\operatorname{sim}$ & 2: insatisfatório \\
\hline 10 & $\operatorname{sim}$ & $\operatorname{sim}$ & não & $\operatorname{sim}$ & 3: satisfatório \\
\hline 11 & $\operatorname{sim}$ & $\operatorname{sim}$ & $\operatorname{sim}$ & $\operatorname{sim}$ & 4: excelente \\
\hline 12 & não & $\operatorname{sim}$ & $\operatorname{sim}$ & $\operatorname{sim}$ & 3: satisfatório \\
\hline 13 & $\operatorname{sim}$ & $\operatorname{sim}$ & $\operatorname{sim}$ & não & 3: satisfatório \\
\hline 14 & $\operatorname{sim}$ & $\operatorname{sim}$ & $\operatorname{sim}$ & $\operatorname{sim}$ & 4: excelente \\
\hline 15 & $\operatorname{sim}$ & $\operatorname{sim}$ & $\operatorname{sim}$ & não & 3: satisfatório \\
\hline
\end{tabular}

Fonte: elaboração própria a partir dos dados da pesquisa 
O único nível de desempenho que contempla todas as características descritas no Quadro 2 é o nível excelente. Nos demais níveis, nem todas as características foram encontradas em um mesmo licenciando, apesar de ser classificado no nível em questão.

De acordo com dados da tabela 1, 4 licenciandos puderam ser classificados no nível excelente que demonstra que os mesmos percebem o erro cometido pelos alunos do caso de ensino, compreendem suas dificuldades e compreendem as razões dessas dificuldades, conseguem fazer questões apropriadas com o objetivo de entender o pensamento do aluno; conseguem elaborar soluções para superar a dificuldade apresentada pelo aluno e conseguem propor atividades pedagógicas condizentes com as dificuldades apresentadas pelos alunos.

Nove dos quinze licenciandos foram classificados no nível satisfatório, mostrando que compreendem dificuldades dos alunos e compreendem as razões dessas dificuldades, conseguem fazer questões apropriadas com 0 objetivo de entender o pensamento do aluno e/ou apresenta situações pedagógicas somente através de questões para superar a dificuldade apresentada pelo aluno.

Dois licenciandos encontram-se no nível insatisfatório, pois percebem o erro dos alunos, mas não o associa às propriedades do Sistema de Numeração Decimal (SND); apresentam dificuldade para entender tanto as dificuldades dos alunos bem como as razões dessas dificuldades; não conseguem fazer questões apropriadas com o objetivo de entender 0 pensamento do aluno nem consegue elaborar soluções para superar a dificuldade apresentada pelo aluno e Não propõe atividades pedagógicas condizentes com as dificuldades apresentadas pelos alunos.

De acordo com a natureza das atividades propostas aos licenciando no trabalho com o caso de ensino, quando estes responderam a essas atividades, três categorias de análise puderam ser destacadas: 1) a percepção do erro dos alunos considerados no caso de ensino e que foram denominados: a1, a2 e a3; 2) questões a serem feitas pelos licenciandos, 
colocando-se no lugar da professora e 3) ações a serem realizadas pelos licenciandos, como professores, diante das dificuldades apresentadas por al, a2 e a3.

\section{DISCUSSÃO DOS RESULTADOS PARA A ATIVIDADE I DO CASO DE ENSINO}

Os desempenhos dos licenciandos diante de uma atividade em um caso de ensino sobre o Sistema de Numeração Decimal (SND) geraram suas classificações nos níveis excelente, satisfatório e insatisfatório (Tabela 1) e as descrições de suas respostas foram agrupadas em 1) Percepção e Compreensão do Erro apresentado pelos alunos do caso de ensino; 2) Questões a serem realizadas aos alunos $\left(a_{1}, a_{2}\right.$ e $\left.a_{3}\right)$ do caso de ensino e 3) Ações a serem realizadas diante das dificuldades dos alunos $\left(a_{1}, a_{2}\right.$ e $\left.a_{3}\right)$ sendo consideradas os resultados para a discussão em termos do referencial teórico adotado na pesquisa e consequente reposta à pergunta que a motivou.

A partir da ideia na qual os casos de ensino "... oferecem oportunidades para que professores e seus estudantes testem seu conhecimento de teoria com a prática (SHULMAN, 1990 apud NONO E MIZUKAMI, 2002, p. 75), o caso de ensino elaborado nesta pesquisa (Anexo 1) versou sobre a representação de quantidades discretas utilizando-se registros do SND. Nesse sentido, a consolidação do conceito de representação numérica, que deveria ser apresentada pelos alunos $\left(a_{1}, a_{2}\right.$ e $\left.a_{3}\right)$, que compunham o contexto do caso de ensino, estava associada às propriedades do SND, tais como: agrupamento na base 10 e valor posicional. Esta mesma associação às propriedades foi tomada como referência na análise dos desempenhos dos futuros professores de Matemática (licenciandos) em ações que foram agrupadas em: 1) Percepção e Compreensão do Erro apresentado pelos alunos do caso de ensino; 2) Questões a serem realizadas aos alunos $\left(a_{1}, a_{2}\right.$ e $\left.a_{3}\right)$ do caso de 
ensino e 3) Ações a serem realizadas diante das dificuldades dos alunos ( $a_{1}$, $\left.a_{2} e a_{3}\right)$.

Dos 15 licenciandos $4\left(L_{4}, L_{8}, L_{11}\right.$ e $\left.L_{14}\right)$ foram classificados no nível excelente, isto porque: 1) perceberam o erro cometido pelos alunos $\left(a_{1}, a_{2} e\right.$ $a_{3}$ ) do caso de ensino; 2) compreenderam a razão ou o porquê da concepção conceitual dos alunos $\left(a_{1}, a_{2}\right.$ e $\left.a_{3}\right)$ expressa em seus erros; 3 ) conseguiram realizar questões apropriadas para revelar a concepção conceitual de $\left(a_{1}, a_{2}\right.$ e $\left.a_{3}\right)$; 4) conseguiram avaliar a resposta de $\left(a_{1}, a_{2}\right.$ e $\left.a_{3}\right)$ critérios apropriados ao domínio da representação numérica no SND e 5) propuseram atividades pedagógicas condizentes com as dificuldades apresentadas pelos alunos.

As respostas desses 4 licenciandos à Percepção e Compreensão do Erro apresentado pelos alunos do caso de ensino, às questões e ações que realizariam evidenciam que seus saberes sobre o SND, necessariamente em relação às propriedades que o regem, foram fundamentais para que pertinentes questões e ações fossem realizadas no contexto apresentado na atividade I do caso de ensino.

Ao buscarem resolver a atividade $I$, os licenciandos $L_{4}, L_{8}, L_{11}$ e $L_{14}$ mostraram intenção de transformar o conteúdo matemático, em conteúdo de ensino, estimulados pelo fato de estarem diante de um evento específico, agindo em um contexto que contemplava intenção, possibilidade, julgamento e reflexão, que para Shulman (1996) são funções que explicam a capacidade dos casos de ensino para que ocorra aprendizagem. Nesse sentido, afirma-se que houve aprendizagem para a docência por parte de $L_{4}, L_{8}, L_{11}$ e $L_{14}$ na atividade I do caso de ensino, pois "Aprende-se a partir do deliberar reflexivamente sobre as relações entre os elementos de um caso (SHULMAN, 1996, p. 207).

Portanto, assegura-se que nesse processo de transformação do conteúdo aprendido na licenciatura em Matemática em conteúdo de ensino, tal como demonstra a utilização de exemplos, de questões, de materiais por $L_{4}, L_{8}, L_{11}$ e $L_{14}$, estiveram mobilizadas operações de 
pensamento como: análise, interpretação, crítica, reflexão, deliberação, levantamento de hipóteses, julgamento, decisão (SHULMAN, 1996; ANASTASIOU E ALVES, 2006).

Também conforme a Tabela 1, 8 licenciandos foram classificados no nível satisfatório, sendo assim classificados de acordo com o Quadro 2, pois: 1) conseguiram realizar questões relacionadas aos desempenhos dos alunos $\left(a_{1}, a_{2}\right.$ e $\left.a_{3}\right)$ com o objetivo de entender seus pensamentos $\left(L_{5}, L_{6}, L_{12}, L_{13}\right.$ e L15); 2) apresentaram situações pedagógicas idênticas às questões que realizariam ( $L_{12}$ e $L_{13}$ ) e 3) associaram atividades pedagógicas à utilização de jogos, Material Dourado, atividades com agrupamentos de quantidades, valor posicional de um símbolo numérico $\left(\mathrm{L}_{3}, \mathrm{~L}_{6}\right.$ e $\left.\mathrm{L}_{7}\right)$.

Apesar de terem sido classificados no nível satisfatório, 3 licenciandos demonstraram dificuldades em termos das ações que realizariam diante dos erros dos alunos $\left(a_{1}, a_{2}\right.$ e $\left.a_{3}\right)$. Assim, "tentaria explicar de alguma outra forma" $\left(L_{5}\right)$, para Jonas e Maria "... somente de fazer com que eles entendam como representar o "0" e para André "... explicar que está correto representar 15 dezenas, mas que o ábaco não admite 15 dezenas", $\left(L_{10}\right)$ e "'Usaria da narrativa para contar-lhes a história de como os primeiros humanos ao pensar nesse sistema encaravam essa representação no cotidiano deles, além disso, problematizaria essa questão pedindo que a exemplo dos antecessores representasse essas quantidades" $\left(L_{15}\right)$.

Diante das respostas dos 8 licenciandos classificados no nível satisfatório, é possível discutir a contribuição de um caso de ensino como recurso formativo na licenciatura a partir das referências curriculares (PARECER CNE/CP 09/01, PARECER CNE/CP 28/01, RESOLUÇÃO CNE/CP 01/02) que subsidiam os cursos de formação de professores que atuarão na Educação Básica.

Se por um lado houve licenciandos que demonstraram ter mobilizado operações de pensamento como: análise, interpretação, crítica, reflexão, deliberação, levantamento de hipóteses, julgamento, decisão discutidas por Shulman (1996) e Anastasiou e Alves (2006), por outro lado, 5 licenciandos 
apresentaram dificuldades para agir reflexivamente em função do observado, pois, pelo fato de estarem no último ano de um curso de formação inicial de professores, o que permite inferir que vivenciaram ações dispostas no Projeto Político Pedagógico do curso, estes futuros professores deveriam estar aptos a reelaborar questões e fazer uso de ações pedagógicas que contribuíssem para a superação de dificuldades apresentadas pelos alunos $\left(a_{1}, a_{2} e a_{3}\right)$. Nesse sentido, retoma-se $a$ necessidade de repensar para a formação inicial do professor de Matemática a ideia de simetria invertida, tal como pressupõe o Parecer CNE/CP 09/2001.

O conceito de simetria invertida ajuda a descrever um aspecto da profissão e da prática de professor, [...] que a experiência como aluno [...] é constitutiva do papel que exercerá futuramente como docente. A compreensão desse fato evidencia a necessidade de que o futuro professor experiencie, como aluno, durante todo o processo de formação, as atitudes, modelos, capacidades e modos de organização que se pretende venham a ser concretizados nas suas práticas pedagógicas. [...] destaca-se a importância do projeto pedagógico do curso de formação na criação do ambiente indispensável para que o futuro professor aprenda as práticas de construção coletiva da proposta pedagógica da escola onde virá a atuar (PARECER CNE/CP 09/2001, p. 30).

Três licenciandos foram classificados no nível insatisfatório, pois: 1) apresentaram dificuldade para entender tanto as dificuldades dos alunos bem como as razões dessas dificuldades; 2) não conseguiram fazer questões apropriadas com o objetivo de entender o pensamento dos alunos $\left(a_{1}, a_{2}\right.$ e $\left.a_{3}\right)$, nem conseguiram elaborar soluções para superar a dificuldade apresentada pelos alunos $\left(a_{1}, a_{2}\right.$ e $\left.a_{3}\right)$ e 3) não propuseram atividades pedagógicas condizentes com as dificuldades apresentadas pelos alunos $\left(a_{1}, a_{2}\right.$ e $\left.a_{3}\right)$.

As respostas de $L_{1}, L_{2}$ e $L_{9}$ evidenciam que a ausência de elementos que compõem o saber do conteúdo pode implicar insatisfatório desenvolvimento ou até mesmo nenhum desenvolvimento do processo de transformação do conteúdo matemático em conteúdo de ensino. A 
resposta de Lq quanto a ações a serem realizadas, "Mostraria onde eles acertaram e erraram para ver e deduzirem onde erram", evidencia isto. Essa resposta remete à sugestão oriunda da pesquisa de Calderhead e Miller (1985) apud Grossman, Wilson e Shulman (1989) na qual existe de fato um "entrelaçar" entre conhecimentos anteriores do professor e aqueles imediatos da sala de aula, bem como dos interesses prévios e conhecimentos dos alunos. As dificuldades apresentadas por $L_{1}, L_{2}$ e $L_{9}$ podem ser consideradas referências para a elaboração de conceitos matemáticos a partir da perspectiva de processos de ensino que ocorrerão em sala de aula da Educação Básica.

\section{CONCLUSÕES}

Ao trabalharem com o caso de ensino, os licenciandos estiveram sob a perspectiva do professor de Matemática, que ensina em sala de aula, tendo a oportunidade de analisar os desempenhos de alunos, seus acertos e dificuldades em relação à representação de quantidades no Sistema de Numeração Decimal (SND). Neste texto, apresentam-se análise e discussões para a Atividade I de um caso de ensino que abordou essa representação.

Em conformidade com as questões que compunham a atividade I foram criadas 3 categorias referentes a conceitos relacionados ao SND: 1) a percepção do erro dos alunos do caso de ensino; 2) questões aos alunos e 3) ações diante das dificuldades apresentadas por estes. Diante dos resultados é possível concluir que o conhecimento dos licenciandos da estrutura e características do SND, em termos de agrupamento e posicionalidade, mostra-se como fundamental para suas capacidades de compreender a natureza e a origem dos erros cometidos pelos alunos do caso de ensino e de realizar pertinentes questões e ações em situação de um professor em sala de aula.

Se houve o tempo de críticas realizadas (GROSSMAN, WILSON E SHULMAN, 1989) a pesquisas denominadas de presságio-produto que 
relacionavam estatisticamente 0 conhecimento do professor com 0 desempenho do aluno, os resultados desta pesquisa, no entanto, não descartam a dedução na qual o conhecimento do professor sobre um conteúdo tem influência no desempenho do aluno. Contudo, esses mesmos resultados permitem reconhecer e considerar, como referência ao saber docente, que o conhecimento necessário para se ensinar (conhecimento pedagógico, transposição didática) pode ser desenvolvido e ampliado a partir da relação deste com competências e habilidades apresentadas pelos alunos. Nesse sentido, casos de ensino sobre conceitos matemáticos, a serem trabalhados na formação inicial de professores, podem ter reconhecido lugar como meio de identificação e desenvolvimento de saberes docentes.

\section{REFERÊNCIAS}

ANASTASIOU, L.G.C; ALVES, L. P. Estratégias de Ensinagem. ANASTASIOU, L. G. C; ALVES, L. P. (ORGS). Processos de Ensinagem na Universidade. Joinville: Univille, 2006.

BRASIL.MEC.CNE/CP. Parecer $\mathbf{n}^{\circ} 09$ de 08 de Maio de 2001. Disponível em http://portal.mec.gov.br/sesu/. Acesso em 20 de Abril de 2014.

BRASIL.MEC.CNE/CP. Parecer $\mathbf{n}^{\circ} \mathbf{2 8}$ de 02 de Outubro de 2001. Disponível em http://portal.mec.gov.br/sesu/. Acesso em 20 de Abril de 2014.

BRASIL.MEC.CNE/CP. Resolução $n^{\circ} 01$ de 18 de Fevereiro de 2002. Disponível

GROSSMAN, P; WILSON, S. and SHULMAN, L. Teachers of Substance: Subject Matter Knowledge for Teaching. (Ed.) REYNOLDS, Maynard. Knowledge Base for the Beginning Teacher. For The American Association of Colleges for Teacher Education. New York: Pergamon Press, 1989.

MERSETH, K. K. Case studies and teacher education. Teacher Education Quartely, Sacramento, v. 17, n. 1, p. 53-61, 1990.

MONTEIRO, A. M. C. Entre Saberes e Práticas: a Relação de Professores com os Saberes que Ensinam. In: ANPED, REUNIÃO ANUAL, 26. Anais Eletrônicos...Rio de Janeiro, 2003.

NONO, M. A. Aprendendo a ensinar: futuras professoras das séries iniciais do ensino fundamental e casos de ensino. 2001. 176 p. Dissertação (Mestrado) Universidade Federal de São Carlos, Programa de Pós-Graduação em Educação, Metodologia de Ensino, São Carlos, 2001 
NONO, M, A; MIZUKAMI, M. G. N. Casos de Ensino e Processos de Aprendizagem Profissional Docente. Revista Brasileira de Estudos Pedagógicos, Brasília, v. 83, n.203/204/205, p. 72 - 84, jan/dez 2002.

NONO, M. A; MIZUKAMI, M. G. N. Casos de Ensino e Processos Formativos de Professoras Iniciantes. MIZUKAMI, M. G. N; REALI, M. M. R. (Orgs). Processos Formativos da Docência: conteúdos e práticas. São Carlos: EdUFSCar, 2005.

OLIVEIRA, R. G. Estágio supervisionado participativo na licenciatura em matemática, uma parceria escola-universidade: respostas e questões. Tese de Doutoramento. São Paulo: s.n., 2006.

SHULMAN, J. H. Happy Accidents: Cases as Opportunities for Teacher Learning. Disponível em: www.wested.org/online_pubs/selectedpublications.pdf Acesso em 24 de fev/2014.

SHULMAN, L. S. Knowledge and Teaching: Foundations of the New Reform. Harvard Educational Review, vol. 57, n 1, p. $1-22,1987$.

SHULMAN, L. S. Those Who Understand: Knowledge Growth in Teaching. Educational Researcher, v. 15 n.2, p. 4 - 14, 1986.

SHULMAN, L. S. Just in case: reflections on learning from experience. In COLBERT, J.; TRIMBLE, K.; DESBERG, P. (Eds.). The case for education. Contemporary approaches for using case methods. Needham Height: Allyn Bacon, 1996, p. 197-217.

TURNUKLU, E. B.; YELSIDERE, S. The Pedagogical Content Knowledge in Mathematics: pre-service primary mathematics teachers' perspectives in Turkey. IUMPST: The Journal. v. 1, p. 1-12, 2007.

WILSON, S. A Case Concerning Content: Using Case Studies to Teach Subject Matter. Disponível em: http://ncrtl.msu.edu/http/craftp/html/pdf/cp891.pdf, acesso em 06.jun/2014.

WILSON, S; SHULMAN, L. and RICHERT, A. '150 Different Way' of Knowing: Representations of Knowledge in Teaching. In: CALDERHEAD, J. (Ed.). Exploring Teachers' Thinking. London: Cassel, 1987.

Recebido em: Março de 2017 Aceito em: Abril de 2017 